\title{
DOCUMENTING HYDRAULIC DEVICES AT RISK IN DEFENSIVE HERITAGE OF AL-ANDALUS THROUGH PHOTOGRAMMETRIC TECHNIQUES
}

\author{
S. Peñalver-Martín ${ }^{1}$, L. J. García-Pulido ${ }^{2}$ \\ ${ }^{1}$ University of Málaga, Spain - s.penalver.martin@gmail.com \\ ${ }^{2}$ Dept. of Art and Architecture, University of Málaga - luis.garcia@uma.es
}

Commission II, WG II/8

KEY WORDS: Al-Andalus, Islamic Heritage, photogrammetric model, fortress, hydraulic system.

\begin{abstract}
:
Most of the Islamic fortresses conserved in the south of the Iberian Peninsula are in rural environments, isolated from any population, and are in an important state of degradation and unawareness. One of the main remains of these constructions are usually the cisterns that supply water to these fortresses, an essential element for the subsistence and the evolution of these settlements. This research aims to study these hydraulic elements and others preserved in these fortresses, as well as the evolution of the fortresses itself since their development is irremediably linked.
\end{abstract}

An essential part of the study of these ensembles is the elaboration of an accurate and versatile graphic documentation that reflects its current state, its construction and its position in the territory. However, their situation in inaccessible places and their state of conservation hinders this task. Therefore, this paper shows a methodology based on the survey of photogrammetric models at an aerial and terrestrial level, from which the necessary documentation has been developed in order to advance in their knowledge, and also constituting an important basis for their cataloguing and dissemination. The study of these fortresses and, especially, their hydraulic systems, is essential for the knowledge and, therefore, the safeguarding of this heritage.

\section{INTRODUCTION}

The area of the Iberian Peninsula dominated by different Islamic kingdoms (711-1492 a.c.), known as al-Andalus, has a wide network of fortresses and alcazabas that were territorial centres of control and defence. Beyond the alcazabas that headed the main population centres, there were a large number of rural fortresses whose function was to establish control points against external threats, being able to accommodate a variable number of soldiers and the population of the surroundings. Its scale and its shelter and supply capacity vary according to the importance that acquired at each time. However, many of these constructions share several common characteristics, among them, their situation in high places for better control of the surroundings and that supposed advantage in the defence; places, therefore, difficult to access in many cases and with strong conditioning factors in their supply.

It should be noted that all these constructions are catalogued as Cultural Heritage Assets (Bienes de Interés Cultural - BIC). However, their situation in remote places has caused their abandonment and progressive deterioration. This situation requires an important work of documentation and cataloguing so that these fortresses do not end up disappearing, not only in a physical sense, but in the memory of the populations, and to create a solid base for future studies and intervention projects.

In this context, a research whose objective is to identify, document and analyse the hydraulic systems that supplied these fortresses, from the preserved remains, it is been developed. The study of the hydraulic networks is irremediably linked to the fortresses and the topographic conditions in which they are inserted. In turn, the analysis of the functioning and evolution of each fortress requires the analysis of its hydraulic network.
1.1 Fortresses and hydraulic systems: from cisterns to spread elements. Research goals.

The research is focused on Islamic fortresses of the provinces of Granada, Málaga and Almería, that will be studied according to a set of overall objectives:

- To document the cisterns preserved in the Andalusian fortresses and analyse their construction systems, their operation as part of the hydraulic network, and their role in the occupation and evolution of the fortress itself.

- To explore the presence of other preserved remains belonging to the hydraulic supply network, inside the walled enclosure and in its surroundings (wells, channels, aqueducts, dams, etc.)

- To study the topography on which the fortresses are based, and the possible modifications caused to facilitate the collection and conduction of water.

- To analyse the evolution of the fortress, as support to understand the development of the hydraulic network and the possible dating of its elements.

So far, it has been documented some cases in Granada, located in the Comarca de los Montes (west), on the northern slope of Sierra Nevada, in the mountains surrounding the Valle de Lecrín and on the coast (south) (Fig. 1).

Some of them are situated in urban environments (fortress of Loja), while others are on prominent hills next to a town (fortresses of Montefrío and Moclín), on the coastline (fortress of La Rijana), or in isolated hills, sometimes continuing

\footnotetext{
* Corresponding author
} 
mountain ranges (fortresses of Los Guájares, Mondújar, Aldeire, Dúrcal, Cabrera and Píñar).

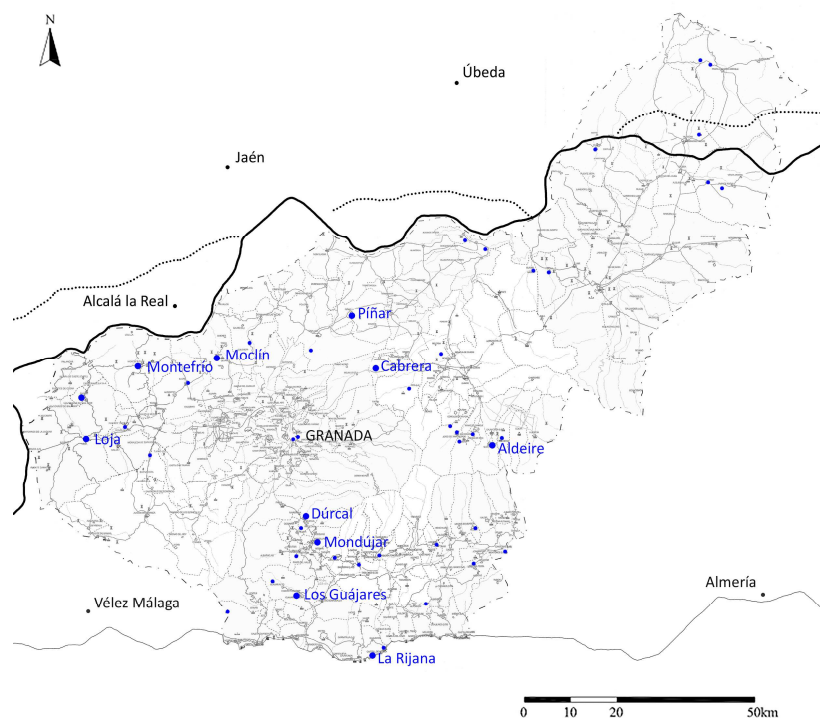

Figure 1. Fortresses documented so far in the province of Granada.

\section{3D SURVEY FOR THE DOCUMENTATION AND RECOGNITION OF THE RURAL FORTRESSES. METHODOLOGY}

The elaboration of the graphic documentation of this research is based on detailed photogrammetric surveys, which are conditioned for several reasons.

On the one hand, the situation of these constructions in remote places and with rough topography, to which is added their different states of conservation. Many of them are in an advanced state of ruin, so that their emergent remains are limited and, in many cases, it is the topography itself that indicates the limits of the fortress, as well as the footprint of the buildings that have disappeared or that are buried. In these cases, it is necessary to elaborate accurate photogrammetric models of the land in which they settle, with a detail level that allows analyzing all the singular points that, in situ, can go unnoticed.

It is also necessary to document in detail the surrounding topography in cases in which the fortresses are located in areas of extreme relief, making it even difficult to locate the construction (Cabrera and Rijana fortresses) (Fig. 2), or in areas that are part of a mountainous context. In these cases, neither the functioning of the fortress nor the hydraulic supply systems (Mondújar and Guájares fortresses) can be understood if the topography is not well analysed.

In other cases, these fortresses dominate an isolated hill, linked in more o less extent to a population, and conserve an important part of their constructions, at least, of its walled enclosure (Moclín, Montefrío, Pínar, Loja, and Los Guájares). In these cases it is essential to document both the surrounding topography and the existing buildings with a high detail level, especially when the density of dwellings inside these enclosures is high, as the case of Los Guájares (Fig. 3), or when the remains appear spread or between dense vegetation, as in Montefrío.
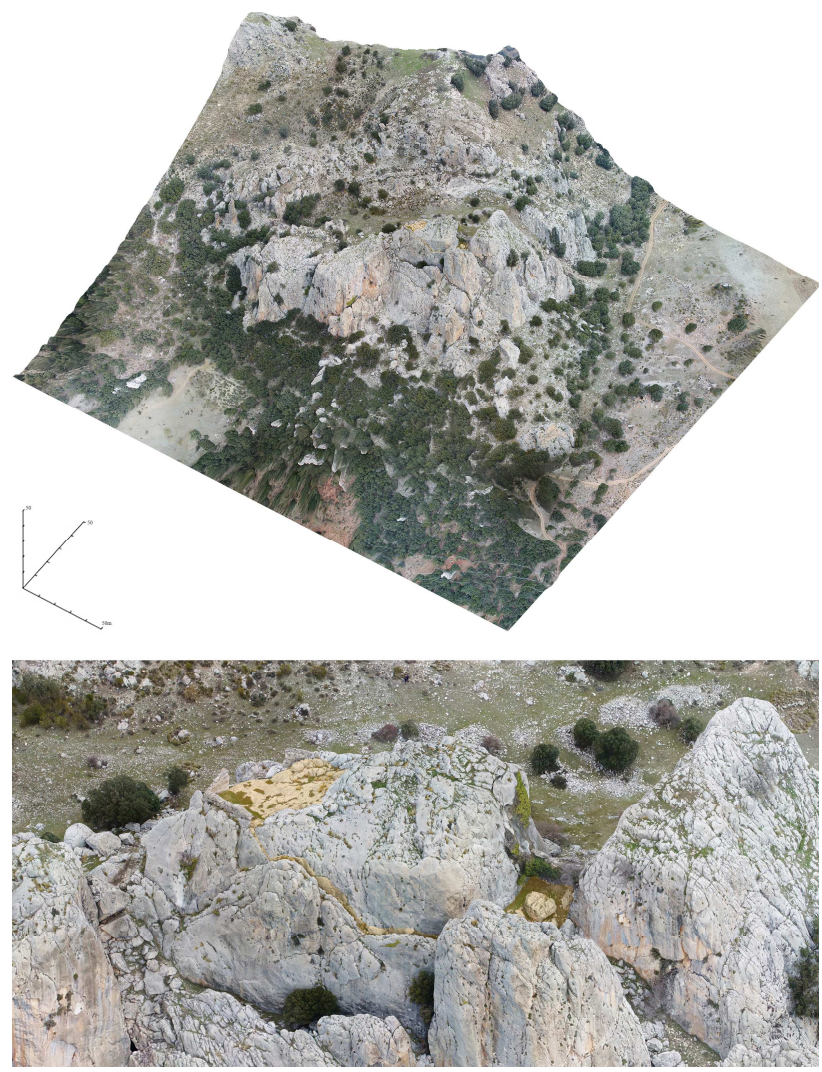

Figure 2. 3D photogrammetric model of the fortress of Cabrera. General view and detail of the location of the fortress, on the top of the rocky hill.

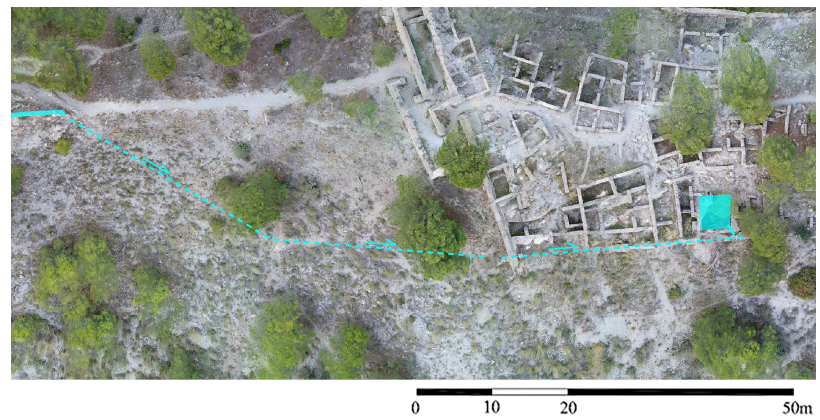

Figure 3. Orthophotograph of the fortified settlement of Los Guájares. Situation of the cistern and hypothesis of the water supply system.

On top of all of this, to understand the construction and the evolution of these ensembles, it is necessary to study the buildings and the remains that are conserved, in a detail level that allows a constructive and material analysis.

In addition, the photogrammetric documentation of the cistern spaces is conditioned, not only by the surrounding itself (presence of abundant vegetation, strong slopes, etc.), but by the different situations in which these can appear. Some of them remain as open spaces buried or semi-buried to which you can freely access; however, others conserve most of their structure, so the entrance to their inside and the light conditions they present can be very limited. 
Due to this broad range of contexts, in order to carry out a global and integrated analysis of these fortresses, it is necessary to establish a work process that is able to combine two levels of documentation, both in the data collection to carry out the survey as in the subsequent processing work of the photogrammetric models: territory and fortresses (landscapearchitectural level) and singular elements (architectural level).

The methodology developed in this research is linked with the survey work conducted in the R+D+I projects "Medieval and modern towers preserved in Andalusia. Graphic survey, scientific analysis and interrelations" (PRY/259/17, Centro de Estudios Andaluces, Junta de Andalucía) and "The watchtowers that defended the Nasrid kingdom of Granada. Analysis and scientific documentation" (HAR2016-79689-P, Ministerio de Economía, Industria y Competitividad) led from the University of Málaga.

The process of documenting the case studies related to the survey process is structured in the following phases:

Previous documentation work:

Preparation of plans and satellite images to support the fieldwork, identification of the preserved remains, and planning of the photographic shot and the measurement tasks.

Fieldwork in each fortress:

Data capture, shooting process by digital cameras (terrestrial photogrammetry) and multicopter (aerial photogrammetry), and development of measurement tasks.

- Processing the information obtained in the laboratory, at both terrestrial and aerial level, and development of photogrammetric models.

- $\quad$ Post-processing of photogrammetric models: Obtaining orthophotographs and digital elevation models, and development of plans.

\subsection{Ground and aerial documentation}

The aerial photographic shot is suitable for these cases of study since it allows working on a large scale, defining the terrain and the fortress in sufficient detail level $(0.10 \mathrm{px} / \mathrm{m})$; however, it does not allow a high definition of singular parts of the construction and of the terrain, and this affects especially the case of cisterns, for several reasons.

The vast majority are half-buried and need a closer photographic shot (2-1 $\mathrm{m}$ distance) to define correctly their geometry, depth, and materiality. On the other hand, those that are totally or partially covered, require a suitable photographic shot to an interior space. There is also the case of cisterns or other buildings that are under a thick layer of vegetation, so they can only be documented by terrestrial photogrammetry. In addition, any remaining pipes or small elements related to the hydraulic network are masked in the definition of the terrain itself, so they need, like the cisterns, a closer detail.

For this reason, the documentation and survey work on each fortress is organized at two levels. On one side, the enclosure of the fortress and its surroundings; on the other, the singular elements that need a greater detail level. This is the case of cisterns and other hydraulic elements, such as small aqueducts, wells and channels.

The documentation of the fortress and its surroundings corresponds to a Landscape scale (1:200-1:5000), in which the systems involved are: aerial photogrammetry + Global Navigation Satellite System (GNSS) as passive systems, and total station as an active system.

The case of cisterns, towers, walls and other architectural remains, corresponds to an Architectural scale (1:20-1:200), in which the systems involved are: close-range aerial photogrammetry + GNSS + terrestrial photogrammetry as passive systems, and total station as an active system (Rodríguez-Gonzálvez et al., 2017).

The equipment for photographic shooting consists of two digital cameras (one of 18 Mpixels and variable focal 18-55mm; another of 22 Mpixels and focal of 14, 20 and $28 \mathrm{~mm}$ ), used for the terrestrial photogrammetry work, and of a multicopter with a compact camera (18 Mpixels and fixed focal length equivalent to $28 \mathrm{~mm}$ ), used for the aerial photogrammetry work.

Measuring tasks are made by a Leica total station with pinpoint electronic distance measurement system (EDM) and with a centimetre accuracy at ranges up to $2 \mathrm{~km}$ from a reference station. It is supported by a laser distance metre in inside spaces where it is not feasible to access with the total station.

First, a series of flights are made with the multicopter that, by means of orthogonal and oblique photographs, cover the near surroundings of the fortress at a long distance, and the fortress at a closer distance, allowing to obtain a good detail of the geometry and the construction (Almagro, 2004; Almagro, 2015).

In parallel, the photographic data collection is made at the ground level of each singular element that needs to be documented in close detail, as well as the elements that may be hidden in the aerial shooting, usually because of the existence of dense vegetation.

In this research, the documentation of the cisterns takes an essential role, where a close shooting of the outside and inside is made in a systematic way, whether it is preserved as a closed space, or if it has lost its cover.

In the event that the cisterns conserve its roof, the holes are usually limited to the oculus and openings to pull out water, to breaks that have suffered their walls, or to the disappearance of the front elevations above ground level. The amount of light that enters to their inside sets up the shooting; therefore, in these cases, it is necessary to use a tripod and a significant investment of time (Fig. 4).

If they have lost part or all of their cover, lighting conditions lighten the work. However, it is necessary to make a close shooting to obtain the maximum detail of materials and functional and constructive details (Fig. 5).

Finally, measurement tasks are carried out using the total station, relating outside-inside of the fortress and outside-inside of the cisterns. This allows, in the subsequent processing of the data, to adjust the accuracy of the models, as well as to orient them geographically and, above all, to combine both levels of work if necessary. 

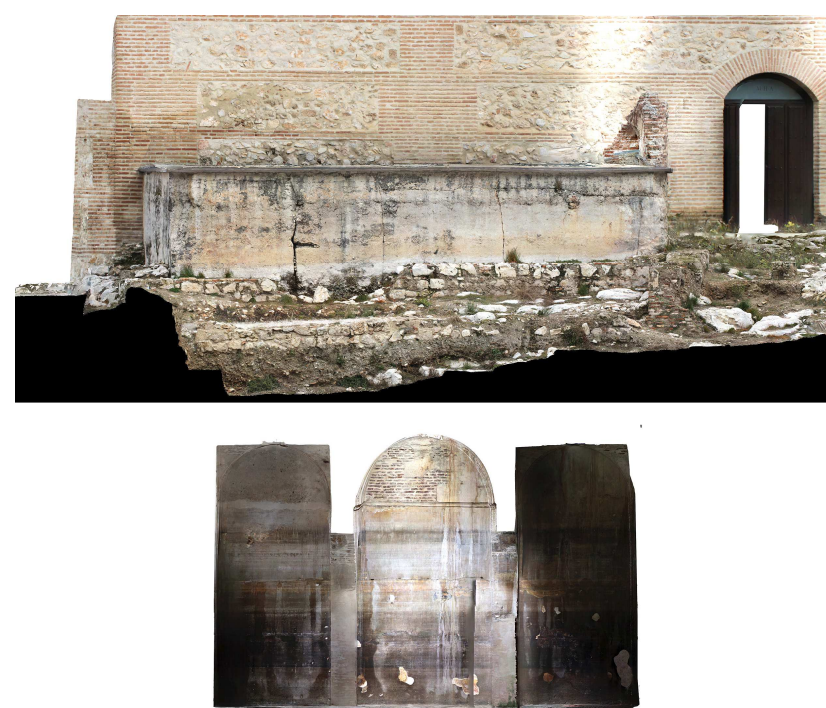

Figure 4. Outside and inside orthophotographs of the cistern of the fortress of Loja.
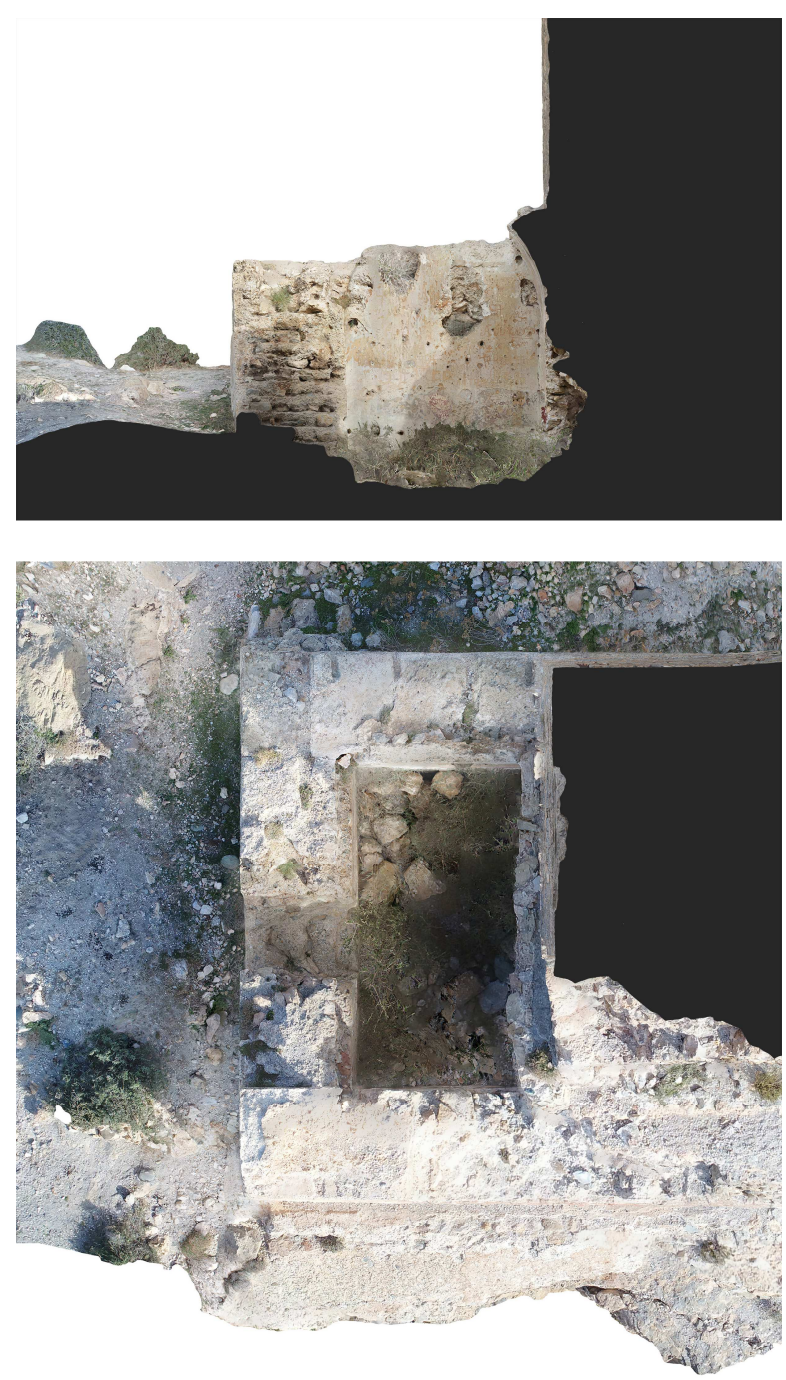

Figure 5. Orthophotographs of the upper cistern of the fortress of La Rijana.
In some cases, the use of the total station is limited. This happens, for example, when the cisterns have great depth or preserve its domes, and the access to their inside is not easy. In these cases, a laser distance meter is used to take the necessary measurements for its subsequent dimensioning, and a total station to take some reference points of the inside of the cistern, from its outside, to allow the link of both models in the laboratory.

Working at different levels allows optimizing both the process of data collection, adapting it to the different conditions offered by each case study, as well as the time of processing in the laboratory.

\subsection{D photogrammetric models. Data processing at two} levels

From the data obtained in the fieldwork phase, different 3D photogrammetric models are developed, maintaining both territorial and architectural level.

- A model of the surroundings, in which the geometry of the fortress is defined, in general terms.

- Models of existing cisterns that define its geometry, construction and material details at a close scale (1:20-1:200). In the case that it preserves its domes, is made an outside and an inside model. Both are joined later on by the reference points taken with the total station.

The first one allows analysing the situation of the construction in the surroundings, in relation to the existing topography. At the same time, it provides us with a framework in which we can comprehend globally the fortress itself, locating all the zones and elements that compose it. Also, it enables to analyse in depth irregularities of the land or possible anthropic modifications of the surroundings (Figs. 6, 7).

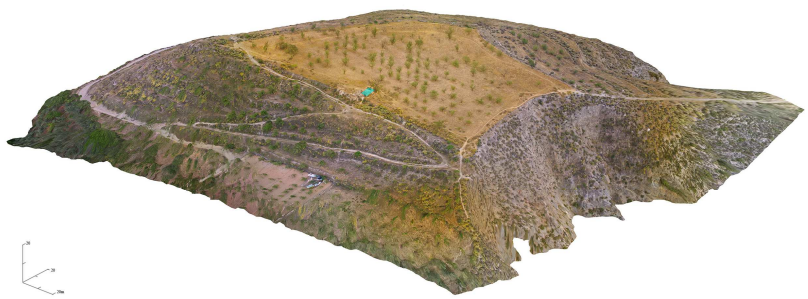

Figure 6. Photogrammetric model of the fortress of Dúrcal.

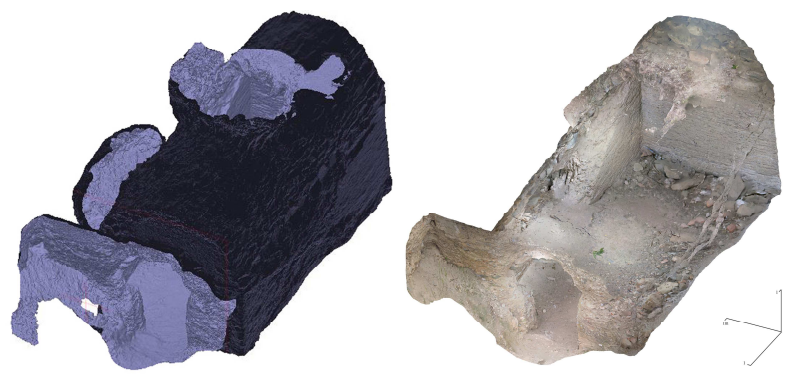

Figure 7. Cistern of the fortress of Dúrcal. Mesh and inside axonometric view. 
In addition, a Digital Elevation Model (DEM) is made from the territorial photogrammetric model. This allows obtaining contour lines at different intervals, defining the topography with the required precision. In these cases study, contour lines are extracted in intervals from $1 \mathrm{~m}$ (large extensions or slopes) to $0.1 \mathrm{~m}$ (slight differences in level or need for high detail) (Fig. $8)$.

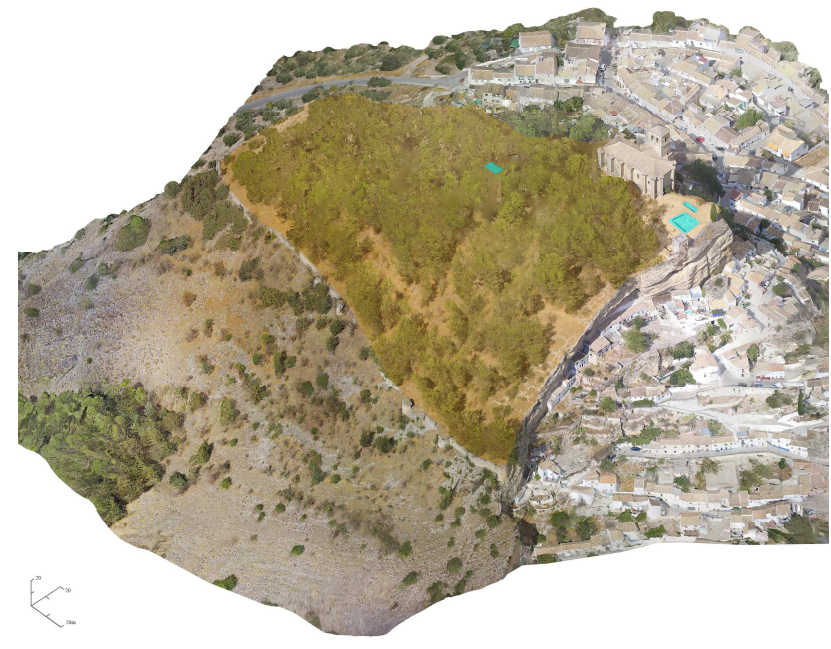

Figure 8. Photogrammetric model of the fortress of Montefrío.

In parallel, photogrammetric models of each of the cisterns or singular constructions are made. Working at this close level facilitates to have these elements defined with greater accuracy in terms of geometry, as well as a high detail on the orthophotographs, that is, on the texture.

In this context, the data obtained from the total station enable not only to scale up and get more accuracy, but also to link different models to check their topographic relationship or to define completely (outside-inside) a cistern that conserves its cover (Fig. 7, 9, 10).

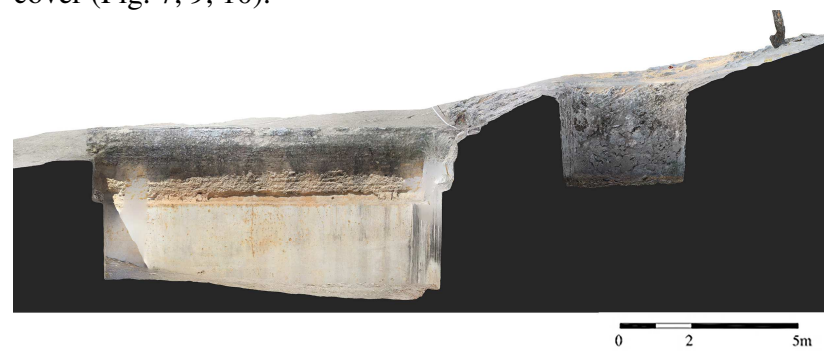

Figure 9. Section of the two upper cisterns of the fortress of Montefrío.

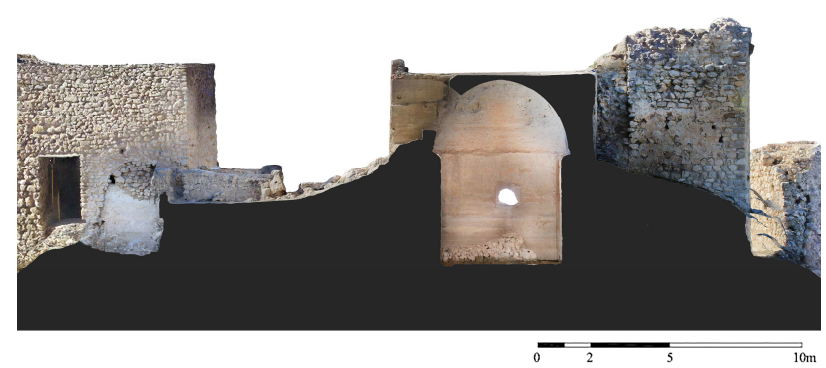

Figure 10. Section of the two cisterns of the fortress of Moclín.

\subsection{D documentation results}

From the developed models, the following documents are systematically extracted.

First, orthophotographs of the surroundings, the walled enclosure and the singular elements, at different resolution levels depending on the degree of detail needed $(0.05 \mathrm{px} / \mathrm{m}$ $0.001 \mathrm{px} / \mathrm{m}$ ). These documents, as well as the contour lines, are the basis for the development of plans from the territory and the topography, to the constructive level.

Orthophotographs and plans are essential documents for constructive and stratigraphic analysis that can provide data on the evolution of these constructions, as well as to analyse the relationship of each fortress with its environment and existing populations, and its role in the network of defensive constructions of the territory.

Having a 3D model that faithfully represents the construction and the topography itself, allows us to obtain fairly accurate sections of the terrain. These documents provide valuable information regarding the construction process and the implementation of these constructions in the surroundings, but also a detail definition of the terrain. This is fundamental in the study of the functioning of the hydraulic system that supplied the fortresses, in relation to the water collection, to the conduction to the fortress, and to the possible links between different cisterns.

Therefore, it is essential to this research to develop a digital elevation model that allows us to obtain the highest accuracy in the definition of the topography. In particular, contour lines are drawn at intervals of $1 \mathrm{~m}$ on the territorial scale, and $0.1 \mathrm{~m}$ on the nearby scale (immediate and interior of the fortress, or outside areas in the case that constructive remains are conserved).

On the other hand, the 3D models developed constitute an important basis for future dissemination and cataloguing phases contemplated in the research and, above all, for the implementation of BIM methodology. It is considered that this line of work is essential for a deep definition of these constructions at different levels, constituting an advance in their knowledge and a solid base for the development of intervention projects.

\section{RESULTS AND FUTURE WORKLINES}

In the first place, it can be highlighted the importance of this type of studies focused on the documentation of these constructions. Precisely because they are in rural environments, some of them far from any population, they present a state of abandonment, and progressive forgetfulness and deterioration, that can cause its material disappearance and in the collective memory itself.

In this sense, the research covers a spectrum that is of special importance, from the development of a strong work of graphic documentation through the elaboration of detailed and accurate plans at different levels, to its situation, definition and cataloguing in territorial databases of open access (heritage information systems), and the development of 3D models that faithfully represent their current status and are an essential document in BIM methodology develop. 
So far, photogrammetric survey of the mentioned fortresses has been developed, obtaining orthophotographs, 3D models of the constructions and digital elevation models, from which plans of the surroundings, the walled enclosure and the conserved elements have been developed, as well as a deep analysis of the preserved remains and the possible evolution of each case.

\subsection{Implementation of an integrated GIS-BIM workflow: towards best practices on restoration and conservation}

On the basis of the developed documentation, two worklines are opened.

In the first place, the integration of the 3D models and the information obtained in each study case in a GIS database allows systematizing and normalizing the data and the information collected. This facilitates the integration, analysis and consultation of information by other researchers, and contributes significantly to the generation of a database on architectural heritage in rural environments, ensuring and facilitating their knowledge.

In addition, it constitutes a fundamental workline in the study of buildings and hydraulic supply systems, since it allows linking the analysis of each case study with topographic and hydraulics databases.

On the other hand, the implementation of BIM methodology in the developed models is a long journey, fundamental in the development of a database that achieves greater efficiency in the knowledge of heritage, in the face of future intervention projects, excavation and restoration (VV.AA., 2018)

This workline is contemplated in the research from the integration of the 3D models in tools and online databases already developed that allow advancing in its constructive definition and evolution, for example, PetroBIM (Armisén et al., 2016). In addition, it is proposed to incorporate these models to the main BIM methodology software, adding this case study to the multiple lines of research that are being developed around the search for greater rigour in the representation of built heritage in BIM methodology (Dore, Murphy, 2012), (Utrero et al., 2016), (Oreni et al., 2017).

All of these worklines will allow incorporating the knowledge of these constructions into a global system of documentation, representation and knowledge. The study of these hydraulic systems has not been undertaken and will help to safeguard this fragile heritage that is in constant risk of deterioration and destruction.

\section{REFERENCES}

Almagro Gorbea, A., 2004. Levantamiento arquitectónico. Universidad de Granada, Granada.

Almagro Gorbea, A., 2013. Surveying World Heritage Islamic Monuments in North Africa: Experiences with Simple Photogrammetric Tools and no Previous Planning. ISPRS Annals Photogramm. Remote Sens. Spatial Inf. Sci., II-5/W1, pp. $13-18$.

Almagro Gorbea, A., 2015. Métodos para documentar y restaurar zonas de difícil acceso en el Castillo de Salobreña. Granada. In: Defensive architecture of the Mediterranean: XV to XVIII centuries, P. Rodríguez Navarro (Ed.), vol. 1, pp. 257264 and $287-290$

Almagro Gorbea, A., 2016. Dibujar la arquitectura de AlAndalus: la base de un método de investigación. In: Dibujo y arquitectura. 1986-2016, treinta años de investigación. Ed. Universidad de Alcalá de Henares, pp. 2-34.

Armisén, A., García, B., Mateos, F. J., Valdeón L. y Rojo, A., 2016. Plataforma virtual para el diseño, planificación, control, intervención y mantenimiento en el ámbito de la conservación del patrimonio histórico 'PetroBIM'. Euro-American Congress Construction Pathology, Rehabilitation Technology and Heritage Management REHABEND. Burgos, Spain.

Dore, C., Murphy, M., 2012. Integration of Historic Building Information Modeling and 3D GIS for Recording and Managing Cultural Heritage Sites. In: 18th International Conference on Virtual Systems and Multimedia. Virtual Systems in the Information Society. Milan, pp. 369-376.

García-Pulido, L. J., Ruiz Jaramillo, J., Alba Dorado, M ${ }^{\mathrm{a}} \mathrm{I}$, 2017. Heritage survey and scientific analysis of the watchtowers that defended the last Islamic kingdom in the Iberian peninsula (thirteen to the fifteenth century). In: The International Archives of the Photogrammetry, Remote Sensing and Spatial Information Sciences, Ottawa, Canada, Vol. XLII-2/W5, pp. 259-265.

Oreni, D.; Karimi, G.; Barazzetti, L., 2017. Applying BIM to built heritage with complex shapes: the ice house of Filarete's Ospedale Maggiore in Milan, Italy. In: The International Archives of the Photogrammetry, Remote Sensing and Spatial Information Sciences, Ottawa, Canada, Vol. XLII-2/W5, pp. 553-560.

Rodríguez-Gonzálvez, P., Muñoz-Nieto, A. L., del Pozo, S., Sánchez-Aparicio, L. J., González-Aguilera, D., 2017. 4D reconstruction and visualization of cultural heritage: analyzing our legacy through time. In: The International Archives of the Photogrammetry, Remote Sensing and Spatial Information Sciences, Ottawa, Canada, Vol. XLII-2/W5, pp. 609-616.

Rodríguez-Navarro, P., Gil Piqueras, T., Verdiani, G., 2016. Drones para el levantamiento arquitectónico. Aplicación para la documentación de las torres del litoral valenciano. In: Serie: Arquitectura y Urbanismo, $71.16^{\circ}$ Congreso Internacional de Expresión Gráfica Arquitectónica, Alcalá la Real, pp. 11371144.

Utrero, Má Á., Murillo, J. I., Martín, R. M., 2016. Virtual models for archaeological research and 2.0 dissemination: The early medieval church of San Cebrián de Mazote (Spain). In: SCIRES-IT-Scientific Research and Information Technology, Vol. 6, Issue 2, pp. 93-108.

VV.AA., 2018. BIM aplicado al Patrimonio Cultural. Documento 14. Coord.: Armisén, A. In: Guía de Usuarios de BIM. Building SMART Spanish Chapter. 